\title{
ANALISIS KEBUTUHAN PENGEMBANGAN PROGRAM PEMBELAJARAN BIOLOGI RAMAH ANAK BERBASIS LINGKUNGAN
}

\author{
Anggi Tias Pratama ${ }^{1}$ (anggitias@uny.ac.id) \\ Angga Damayanto ${ }^{1}$ \\ Firmansyah $^{1}$ \\ Rizqa Devi Anazifa ${ }^{1}$ \\ Kintan Limiansi ${ }^{1}$ \\ Heru Sukoco ${ }^{1}$ \\ ${ }^{1}$ Universitas Negeri Yogyakarta
}

\begin{abstract}
ABSTRAK
Penelitian ini bertujuan untuk menganalisis kebutuhan pengembangan program pembelajaran biologi yang ramah anak berbasis lingkungan berdasarkan potensi lokal yang ada. Sampel penelitian ini adalah orang tua dan pendidik yang tinggal di daerah Kabupaten Gunungkidul. Teknik sampling yang digunakan adalah purposive sampling berdasarkan tujuan dari analisis kebutuhan. Sementara data dikumpulkan dari hasil wawancara terbuka dan observasi. Hasil observasi lapangan menunjukkan bahwa potensi lokal yang dapat dikembangkan di daerah Kabupaten Gunungkidul di antaranya adalah; 1) adanya potensi Gua Pindul, Gua Si Oyot, dan pantai sundak yang dapat digunakan sebagai sumber pembelajaran ekologi; 2) beberapa tanaman seperti pohon Tectona grandis dan Melaleuca leucadendra yang berpotensi untuk dikembangkan sebagai bahan ajar. Hasil wawancara dengan beberapa orang tua dan pendidik menunjukkan bahwa selama ini pembelajaran yang dilakukan masih belum ramah untuk anak terutama bagi para penyandang disabilitas. Kesimpulan dari hasil analisis kebutuhan ini adalah diperlukan sebuah pengembangan program pembelajaran yang dapat mencakup semua kalangan masyarakat termasuk adalah anak berkebutuhan khusus terutama pada mata pelajaran Biologi.
\end{abstract}

Kata Kunci : Analisis kebutuhan, pengembangan program pembelajaran ramah anak, berbasis potensi lokal.

\begin{abstract}
This study aimed to analyze the needs of the development of biology learning program based childfriendly environment based on local potentials. Samples were taken from parents and educators who live in the area of Gunungkidul Regency. The sampling technique used was purposive sampling based on the objectives of the need analysis. At the same time, data is collected from the results of open interviews and observations. The results of field observations show that the local potential could be developed in the Gunungkidul Regency are; a) there is the potential of Pindul, Si Oyot Caves, and the Sundak beach that can be used as a source of ecological learning; b) some plants such as the Tectona grandis and Melaleuca leucadendron trees have the potential to be developed as teaching material. Interviews with parents and educators showed that during this learning is done still not friendly to children, especially for persons with disabilities. The conclusion of this needs analysis has required the development of learning programs that can include all the community, including children with special needs, are especially on the subjects of Biology.
\end{abstract}

Keywords: Analysis of needs, the development of child-friendly learning programs based on local potential.

\section{PENDAHULUAN}

Education for all (pendidikan untuk semua) merupakan sebuah sistem pendidikan ramah anak yang mengupayakan agar setiap warga negara dapat memenuhi haknya, yaitu layanan pendidikan (DPR RI, 1999). Pembelajaran untuk semua merupakan wujud pembelajaran yang menyangkut semua usia entah itu dewasa, orang tua maupun anak-anak yang bertujuan agar lebih mengerti tentang sesuatu. Pendidikan merupakan suatu wadah sentral memiliki potensi yang besar dalam mengembangkan ilmu pengetahuan serta wawasan yang berteknologi. Pembelajaran biologi sebagai salah satu bagian dari pendidikan memiliki potensi yang besar dalam memanfaatkan lingkungan sebagai sumber belajar (Madya \& Ishartiwi, 2017). Salah satu pemanfaatan lingkungan adalah dengan mengkaji potensi lokal yang ada di lingkungan 
sekolah. Pembelajaran materi ilmu lingkungan dapat dilakukan dengan cara turun langsung ke lapangan sehingga peserta didik dapat melihat kejadian-kejadian yang ada di lingkungan sekitar sebagai sumber belajar.

Lingkungan di sekitar sekolah dapat dimanfaatkan sebagai sumber belajar yang baik. Melalui pembelajaran yang memanfaatkan lingkungan belajar dalam kegiatan pembelajaran dapat meningkatkan pengetahuan konseptual dan literasi lingkungan peserta didik yang dibutuhkan dalam kehidupan abad 21. Hal ini sejalan dengan (Hw, Paidi 2012) dan Yustiana I 2018) yang mengungkapkan beberapa alasan dalam penggunaan lingkungan di sekitar sekolah sebagai bahan, konteks dan sumber belajar yaitu: lingkungan dapat memperkaya bahan dan kegiatan belajar; penggunaan lingkungan memungkinkan terjadinya proses belajar yang memberikan pengalaman langsung sehingga membuat pembelajaran lebih bermakna dan fungsional; interaksi yang intensif dengan alam sekitar lebih cenderung menyiapkan perasaan dekat dan positif bagi peserta didik terhadap fenomena alam; memberikan tantangan untuk berpikir kritis dan memecahkan masalah, karena lingkungan menyediakan permasalahan yang ill-structured dan kompleks: mendukung perkembangan peserta didik pada bidang kognitif, emosional dan psikomotor. Selain itu, pemanfaatan kearifan lokal sebagai sumber belajar dapat menyelamatkan pengetahuan budaya lokal dan juga membantu peserta didik melalui pembelajaran dunia nyata (Hadi, 2017) dan (Hadi \& Dazrullisa, 2018).

Gunungkidul merupakan salah satu Kabupaten yang ada di Daerah Istimewa Yogyakarta. Luas wilayah Kabupaten Gunungkidul 1.485,36 km2 atau sekitar 46,63 \% dari luas wilayah Daerah Istimewa Yogyakarta. Kota Wonosari terletak di sebelah tenggara kota Yogyakarta (Ibukota Daerah Istimewa Yogyakarta), dengan jarak $\pm 39 \mathrm{Km}$. Wilayah Kabupaten Gunungkidul dibagi menjadi 18 Kecamatan, 144 desa, dan 1.431 pedukuhan (Pemerintah Kabubaten Gunungkidul, 2020). Kabupaten Gunungkidul juga mempunyai panjang pantai yang cukup luas terletak di sebelah selatan berbatasan dengan Samudera Hindia, membentang sepanjang sekitar 65 Km dari Kecamatan Purwosari sampai Kecamatan Girisubo, serta memiliki pulau. Potensi hasil laut dan wisata sangat besar dan terbuka untuk dikembangkan.

Potensi lainnya adalah industri kerajinan, makanan, pengolahan hasil pertanian yang semuanya sangat potensial untuk dikembangkan. Selain luas wilayahnya Gunungkidul banyak ditumbuhi oleh pohon jati. Karakteristik pohon jati yang menggugurkan daunnya setiap musim kemarau memberikan sebuah masalah baru bagi masyarakat sekitar. Daun-daun kering yang gugur ini menjadi sampah yang belum dapat dimanfaatkan secara maksimal secara baik dan mengganggu pertanian. Hasil penelitian oleh (Wilujeng et al., 2017) menunjukkan bahwa banyak potensi lingkungan yang dapat dimanfaatkan sebagai sumber belajar. Sejalan dengan penelitian dari (Wilujeng et al., 2019) juga menunjukkan bahwa, pembelajaran yang mengintegrasikan potensi lokal dapat melatih peserta didik untuk dapat mengamati dan melakukan percobaan secara mandiri. Melihat potensi yang dimiliki oleh Gunungkidul, seharusnya pembelajaran Biologi dapat dilaksanakan secara lebih mendalam dengan memanfaatkan potensi kekayaan alam yang dimiliki dengan menggunakan setting pembelajaran yang ramah anak sebagai sistem layanan pendidikan mengharuskan agar semua anak dapat diberikan pelayanan yang ramah dan sesuai dengan kondisi serta kebutuhan mereka ketika berada di dalam lingkungan pembelajaran secara setara tanpa membedakan kondisi mereka baik secara fisik, intelektual, ras dan agama.

Melihat Indonesia yang merupakan salah satu negara dengan tingkat kepadatan penduduk yang tinggi. Tingginya jumlah populasi masyarakat tersebut memiliki dampak timbulnya berbagai macam kesenjangan, baik secara keragaman karakter, suku, ras, agama hingga kondisi kognitif, mental, sensori serta fisik seseorang. Dengan keragaman masyarakat tersebut, Pemerintah Indonesia memiliki strategi dan program tersendiri untuk memenuhi kebutuhan dasar tiap kelompok masyarakat, termasuk masyarakat penyandang disabilitas agar dapat memiliki kualitas hidup yang setara dengan masyarakat non disabilitas. Hal tersebut terjadi karena akomodasi keluarga yang terbatas dan letak sekolah yang sulit dijangkau, belum lagi permasalahan perekonomian yang membuat anak-anak tersebut mengalami kesulitan untuk bersekolah. 
Pratama, A.T., et al., Analisis Kebutuhan Pengembangan Program Pembelajaran Biologi Ramah Anak Berbasis Lingkungan

JURNAL BIOLOKUS Vol.3 (1)

Berdasarkan data dari Kementerian sosial, lebih dari 190 ribu orang penyandang disabilitas tersebar di Indonesia dan di DI Yogyakarta sendiri terdapat lebih dari 6 ribu jiwa, 1,67\% dari jumlah tersebut atau lebih dari 100 orang adalah anak usia 6-18 tahun (Kementerian Sosial). Dengan jumlah yang termasuk besar tersebut, Pemerintah terus berupaya meningkatkan akses ke layanan dasar khususnya dalam hal pendidikan bagi anak dengan disabilitas. Berdasarkan data yang diperoleh Pusat Pemberdayaan Disabilitas Mitra Sejahtera (PPDMS), di Kabupaten Gunungkidul terdapat sekitar 40 anak dengan disabilitas yang tidak dapat bersekolah.

Padahal, dengan bersekolah seharusnya anak akan mendapatkan layanan pembelajaran yang dapat mendukung proses interaksi peserta didik dengan pendidik dan sumber belajar. Karena menurut Sudirjo (2016), pembelajaran merupakan bantuan yang diberikan pendidik agar dapat terjadi proses pemerolehan ilmu dan pengetahuan, penguasaan kemahiran dan tabiat, serta pembentukan sikap dan kepercayaan pada peserta didik. Dengan kata lain, pembelajaran adalah proses untuk membantu peserta didik agar dapat belajar dengan baik. Proses pembelajaran dialami sepanjang hayat seorang manusia serta dapat berlaku di mana pun dan kapan pun. Pembelajaran mempunyai pengertian yang mirip dengan pengajaran, walaupun mempunyai konotasi yang berbeda. Dalam konteks pendidikan, pendidik mengajar supaya peserta didik dapat belajar dan menguasai isi pelajaran hingga mencapai sesuatu objektif yang ditentukan (aspek kognitif), juga dapat mempengaruhi perubahan sikap (aspek afektif), serta keterampilan (aspek psikomotor) seseorang peserta didik. Pengajaran memberi kesan hanya sebagai pekerjaan satu pihak, yaitu pekerjaan pendidik saja. Sedangkan pembelajaran juga mengisyaratkan adanya interaksi antara pendidik dengan peserta didik (Qosim et al., 2015).

Hasil penelitian (Hapsari et al., 2019) bahwa seorang pendidik harus mampu mengembangkan pedagogical content knowledge dalam proses pembelajaran, sehingga pendidik dengan mudah mengatur situasi kelas dan peserta didik juga akan dengan mudah menerima materi. Hal tersebut diperkuat dengan kesepakatan pemerintah yang direalisasikan dalam 17 Agenda Tujuan Pembangunan Berkelanjutan2030 yang disepakati oleh 193 negara yang tergabung dalam United
Nations (UN) dengan slogan "leavenoonebehind". Undang- Undang (UU) Republik Indonesia Nomor 8 Tahun 2016 (DPR RI, 2016). Penyandang Disabilitas menegaskan bahwa Indonesia sangat memperhatikan penyandang disabilitas meliputi hak- hak untuk: hidup, privasi, keadilan dan perlindungan hukum, pekerjaan, berwirausaha, aksesibilitas, mandiri, kesejahteraan sosial, dan sebagainya yang telah diatur dalam UU tersebut.

Hasil dari penelitian-penelitian tersebut menjadi sebuah landasan dalam melakukan penelitian ini untuk menemukan rancangan dan komponen dalam mengembangkan model pembelajaran biologi berbasis lingkungan yang ramah bagi anak, termasuk anak dengan disabilitas di Gunungkidul yang diharapkan dapat mendukung terlaksananya gual ke 4.1 Tujuan Pembangunan Berkelanjutan (TBP) atau yang dikenal dengan Sustainable Development Guals (SDGs) tahun 2030 yang menjamin bahwa semua anak perempuan dan laki-laki menyelesaikan pendidikan dasar dan menengah tanpa dipungut biaya, setara, dan berkualitas, yang mengarah pada capaian pembelajaran yang relevan dan efektif (Badan Perencanaan Pembangunan Nasional, 2017)

\section{METODE}

Penelitian ini menggunakan pendekatan kualiatif dengan teknik pengumpulan data berupa wawancara terbuka dan observasi lingkungan. Sampel dari penelitian ini adalah pendidik dan orang tua siswa yang tinggal di daerah Nglipar, Gunungkidul. Analisis data dilakukan dengan menguji keabsahaan data melalui triangulasi data antara pendidik dan orang tua siswa. Observasi di lapangan dilakukan untuk mengamati potensi lokal yang dapat dikembangkan sebagai pengembangan program pembelajaran Biologi berbasis ramah anak. Sementara indikator wawancara yang digunakan dalam penelitian ini diantaranya adalah; 1) perencanaan pembelajaran yang biasa dilakukan oleh guru di wilayah Gunungkidul; 2) aktivitas kegiatan pembelajaran terutama pada mata pelajaran Biologi, 3) evaluasi yang dilakukan, dan 4) kegiatan pembelajaran ramah anak terutama pada anak-anak berkebutuhan khusus. Adapun rumusan masalah dalam penelitian ini diantaranya adalah; 1) apa saja potensi lokal yang ada di daerah Kabupaten Gunungkidul untuk dapat dikembangkan dalam proses pembelajaran 
terutama pada mata pelajaran Biologi yang ramah anak? 2) bagaimana proses pembelajaran Biologi dilaksanakan mulai dari perencanaan hingga evaluasi yang dilakukan oleh guru di daerah Kabupaten Gunungkidul tersebut? 3) adakah usaha guru dalam pemerataan hak belajar siswa bagi anak-anak berkebutuhan khusus di daerah Kabupaten Gunungkidul tersebut?

\section{HASIL DAN PEMBAHASAN}

\section{Identifikasi Potensi Lokal di Kabupaten Gunungkidul}

\section{Gua Pindul dan Si Oyot}

Gua Pindul adalah salah satu dari gua di daerah Gunungkidul yang dialiri aliran sungai di bawah tanah. Panjang totalnya $300 \mathrm{~m}$ dan lebar rata-ratanya 5-6 m, ke dalam air antara 4-7 m, tinggi permukaan air ke langit-langit gua sekitar 4,5 m, waktu tempuh sekitar 20-40 menit. Gua Pindul terbagi menjadi 3 zona yaitu zona terang, zona remang, zona gelap abadi (Sujarwo, 2013). Di bagian dalam gua terdapat sebuah stalaktit yang sudah menyatu dengan stalagmit sehingga tampak seperti sebuah pilar dengan ukuran lebar lima rentangan tangan orang dewasa. Selain gua Pindul, Gunungkidul memiliki Gua sioyot. Gua Sie Oyot akan menemukan hamparan (ribuan) stalaktit yang masih aktif dan stalagmit yang sudah menyatu dengan stalaktit, dan juga akan ditemui air terjun di dalam perut bumi ini, tetapi air terjun ini berada di balik dinding perut bumi sehingga belum bisa terlihat. Berdasarkan pengamatan di lapangan bahwa potensi gua dalam pembelajaran biologi dapat dijadikan sebagai pengukuran kualitas ekologi gua, seperti kelimpahan biomasa (Surtikanti K Hertien; Bahabazi, 2013). Selanjutnya penelitian (Denti Meiningsih, Siti Alimah, 2019) menemukan bahwa pengembangan modul berbasis kearifan lokal gua dalam pembelajaran ekosistem sangat baik dalam menjaga pelestarian lingkungan dan anak juga dapat memanfaatkan sumber daya yang ada di sekitar, misalnya budidaya ikan dan pariwisata. Sumber belajar di sekitar merupakan pembelajaran yang berhubungan langsung dengan kehidupan nyata, untuk memanfaatkan sumber belajar dalam kegiatan pembelajaran (Irawan \& Susilo, 2014).

\section{Kali Oya}

Kali Oyo dan Gua Pindul merupakan bagian dari bentang alam kars. Gua Pindul merupakan endokars, sedangkan Kali Oyo merupakan eksokars. Sungai yang melewati Desa Bejiharjo ini mempunyai aliran sungai dewasa, yang dicirikan erosi lateral yang sudah mulai berkembang dan lembah sungai berbentuk U. Dengan pemanfaatan potensi sungai dalam pembelajaran biologi, siswa dapat mengenal sungai sebagai komponen ekologi. Hasil penelitian (Irwandi \& Fajeriadi, 2020) menyatakan bahwa siswa yang pembelajaran memanfaatkan lingkungan sungai sebagai sumber belajar mampu meningkatkan minat dan hasil belajar kognitif siswa. Pembelajaran yang sesuai dengan kondisi dan potensi anak dapat dioptimalkan dengan memanfaatkan sungai ('Ulum, 2017).

\section{Pantai Sundak}

Perairan pantai Sundak memiliki beberapa biota salah satunya adalah bulu babi (echinodermata). Bulu babi tersebar di lapisan susunan dan ekosistem karang, keberadaan bulu babi dalam suatu ekosistem tidak dapat dipisahkan dari pengaruh faktor lingkungan pada fisika kimia, walaupun tidak memiliki pengaruh langsung. Perbedaan karakteristik dalam dua ekosistem akan mempengaruhi populasi dalam ekosistem (Firmandana; Suryanti; Ruswahyuni, 2014). Kualitas air Sundak sangat Pantai Sundak juga memiliki potensi sumber daya kelautan yang besar (Musrowati Lasindrang, 2015). Struktur ekosistem dan karakteristik pantai Sundak dapat dimanfaatkan sebagai media pembelajaran biologi. Vitdiawati et al., (2016) menyatakan bahwa pantai dapat dijadikan laboratorium alam siswa dalam pembelajaran ekologi. Selain itu syarat kualitas air di pantai Sundak baik digunakan dalam praktikum.

\section{Lahan Pekarangan}

Lahan pekarangan yang luas dapat dimanfaatkan sebagai lingkungan belajar bagi siswa. Di halaman pekarangan sebagai besar penduduk di penuhi oleh perkebunan dan pertanian. Mayoritas perkebunan adalah Tectona grandis dan Melaleuca leucadendra. Perkebunan Tectona grandis dan Melaleuca leucadendra dapat dimanfaatkan sebagai sumber belajar biologi.

\section{Pembelajaran Biologi yang Ramah Anak}

Pendidikan yang ramah merupakan salah satu perwujudan dari pendidikan inklusif yang bertujuan untuk memberikan hak yang sama kepada seluruh anak tanpa adanya perbedaan apa 
pun kondisi yang ada pada anak. Tetapi pada kenyataannya, berdasarkan hasil wawancara dengan penyandang disabilitas di daerah Gunungkidul, selain jarak sekolah yang jauh sehingga sulit dijangkau, masih banyak juga sekolah di sekitar yang belum bisa memberikan pelayanan secara maksimal pada anak dengan disabilitas karena pemahaman pendidik tentang pelayanan dan penanganan anak dengan disabilitas masih sangat minim. Padahal menurut Andini et al., (2018), untuk mewujudkan masyarakat yang inklusif harus dimulai dari sekolah. Karena sekolah merupakan miniatur masyarakat yang terdiri dari berbagai macam kondisi anak yang beragam seperti yang ada dalam lingkungan masyarakat, sehingga masing-masing anak akan mulai terbiasa dengan berbagai macam keberagaman antara anak yang satu dengan anak yang lainnya. Sehingga dapat memunculkan sikap kepedulian dan kerja sama serta saling menghargai.

Dari hasil wawancara dengan penyandang disabilitas, dapat diketahui bahwa mereka berharap sekolah dapat menjadi salah satu bagian pembelajaran yang akan membentuk dan mengarahkan anak dalam membuat pedoman hidup mereka agar mereka dapat meningkatkan kualitas hidup setelah mendapatkan kualifikasi yang diperlukan. Seharusnya sekolah juga berbicara tentang bagaimana cara menjaga peserta didik agar tetap terhubung dengan budaya, perkembangan teknologi dan komunikasi. Selain itu dalam era 4.0 ini, sekolah seharusnya dapat memperkenalkan peserta didik ke dunia logika pasar sehingga mereka dapat mempelajari bagaimana cara mengatasi tantangan hidup secara umum dan krisis perkembangan kepribadian di era ini. Dari sudut pandang orang tua, tugas sekolah adalah untuk mendisiplinkan peserta didik sedemikian rupa sehingga terjadi transfer pengetahuan, nilai-nilai dan pola tindakan yang menjaga masyarakat menjadi mungkin. Jenis disiplin ini memperkenalkan dan menekankan nilai-nilai seperti saling pengakuan dan menghormati orang lain seperti yang lain. Seperti yang dikatakan oleh Orón Semper \& Blasco (2018) dalam mengatasi perbedaan status sosial di sekolah adalah dengan menggunakan cara yang spesifik dan memperkuat komunitas adalah tujuan yang tidak terlihat dari apa yang disebut hidden curricullums.
Pada kenyataannya tujuan tersebut sering tidak dapat terlaksana dengan baik. Khususnya, sehubungan dengan kesenjangan yang semakin meningkat antara si kaya dan si miskin, si normal dan si cacat di sekolah masih memiliki jalan panjang. Kebebasan dan kesetaraan seharusnya merupakan hal yang saling berkaitan, tetapi selalu saja menjadi sebuah perdebatan karena adanya hegemoni di dalam masyarakat (Gramsci, 1971). Rekonsiliasi tampaknya tidak mungkin dilakukan hanya secara teoretis maupun praktis saja. Oleh karena itu, kebebasan dan kesetaraan harus selalu diikutsertakan ketika membahas secara normatif implikasi sekolah terhadap anak. Sehingga muncullah istilah pendidikan alternatif yang digunakan pada program pendidikan yang disesuaikan dengan ragam kondisi yang ada di masyarakat. Misalnya, kondisi yang terjadi pada anak dengan disabilitas ataupun anak yang berada pada keluarga kurang mampu dari segi ekonomi. Sejalan dengan yang dijelaskan oleh Paulo Freire dalam buku Pendidikan Kaum Tertindas (2011), pendidikan alternatif memiliki persamaan, yaitu: pendekatannya bersifat individual, memberi perhatian besar kepada peserta didik, orang tua/keluarga, dan pendidik serta dikembangkan berdasarkan minat dan pengalaman.

Berdasarkan hasil wawancara terhadap orang tua dan penyandang disabilitas mengenai pembelajaran biologi yang ramah terhadap anak. Sebagian besar orang tua tidak memahami kebutuhan apa saja yang harus diberikan kepada anak mereka untuk pembelajaran biologi. Sedangkan menurut perwakilan organisasi penyandang disabilitas di Gunungkidul yaitu PPDMS, pendidik mata pelajaran biologi masih memiliki pemahaman sempit mengenai pembelajaran yang ramah pada anak karena mereka belum dapat memberikan layanan secara optimal pada anak, khususnya anak dengan disabilitas. Di sisi lain, baik orang tua mapun penyandang disabilitas menginginkan luaran dari sekolah nantinya memiliki kemampuan yang dapat mendukung dan meningkatkan kualitas hidup mereka dengan kondisi dan potensi yang mereka miliki. Dengan demikian seharusnya sekolah dapat menyediakan dan membentuk lingkungan yang dapat menerima dan memberikan layanan kepada semua sebagai bagian dari sekolah. Seperti yang dijelaskan oleh Roo'fah et al., (2010) tentang aksesibilitas dan partisipasi penyandang disabilitas 
Pratama, A.T., et al., Analisis Kebutuhan Pengembangan Program Pembelajaran Biologi Ramah Anak Berbasis Lingkungan

JURNAL BIOLOKUS Vol.3 (1)

di dalam pendidikan tinggi yang dipengaruhi berbagai faktor salah satunya adalah kurikulum dan perangkat pembelajaran lainnya yang harus ramah bagi semua orang, agar tercipta sebuah kesetaraan dalam proses pembelajaran.

Kesetaraan dalam pelayanan pendidikan melalui model pembelajaran biologi berbasis lingkungan yang ramah bagi anak seharusnya dapat digunakan untuk meningkatkan kualitas hidup seluruh anak, termasuk anak dengan disabilitas. Penelitian ini didasari oleh penelitian terdahulu dalam penelitian etnografi home schooling sebagai pendidikan alternatif (Purnamasari et al., 2017) di mana orang tua dan keluarga dapat melibatkan anak dalam menentukan tujuan, metode, pendekatan, materi dan sumber belajar yang disesuaikan dengan situasi, gaya belajar, kondisi serta kebutuhan anak dan keluarga. Hasil dari penelitian model pemberdayaan masyarakat miskin melalui jalur pendidikan non formal di Kecamatan Gajahmungkur Kota Semarang (Mulyono, 2017) menunjukkan bahwa terdapat tiga formulasi supply and demand dalam melakukan pemberdayaan di dalam masyarakat, dalam hal ini berkaitan dengan pemberdayaan keluarga berarti sangat diperlukan sebuah modifikasi dari ketiga formulasi tersebut terkait kondisi dan kemampuan anak (supply) serta target capaian yang harus dicapai oleh anak dan keluarga (demand). Penyesuaian atau modifikasi dari formula tersebut harus disesuaikan dengan kearifan lokal yang ada pada lingkungan sekitar anak seperti yang telah dijelaskan pada hasil penelitian yang dilakukan oleh Madya dan Ishartiwi (2017) di mana pendidikan karakter harus dikembangkan terus menerus melalui siklus aksi permodelan peran, komunikasi dua arah, pengambilan keputusan partisipasi dan keterlibatan peserta didik dalam mengamati nilai-nilai budaya yang ada di sekitar.

\section{PENUTUP}

Berdasarkan hasil penelian dan analisis dapat disimpulkan bahwa, pelaksanaan pembelajaran yang ada di Gunungkidul masih belum ramah terhadap anak, khususnya pada anak dengan disabilitas. Hal tersebut tejadi karena minimnya pemahaman baik dari sisi orang tua maupun pendidik tentang pentingnya pembelajaran yang ramah bagi semua anak, khususnya pada pembelajaran biologi, melihat berbagai potensi yang dimiliki oleh Kabupaten Gunungkidul yang seharusnya dapat mengoptimalkan pembelajaran secara maksimal sehingga anak dapat memaksimalkan potensi yang mereka miliki untuk meningkatkan kualitas hidup mereka kelak. Oleh karena itu sangat diperlukan sebuah pengembangan model pembelajaran yang ramah anak berbasis lingkungan dalam pembelajaran biologi di Kabupaten Gunungkidul dengan memaksimalkan potensi lokal yang dimiliki oleh Kabupaten Gunungkidul yang dapat dapat mendukung pembelajaran untuk semua anak.

\section{REFERENSI}

'Ulum, I. (2017). Pemanfaatan Lingkungan Sebagai Sumber Belajar Anak. Jurnal Pendidikan Anak, 3(2), 518-523.

https://doi.org/10.21831/jpa.v3i2.11707

Andini, D. W., Rahayu, A., Budiningsih, C. A., \& Mumpuniarti, M. (2018). Pandangan Kepala Sekolah Mengenai Pendidikan Inklusif Dan Anak Berkebutuhan Khusus Di Sekolah Dasar Diy. TAMAN CENDEKIA: Jurnal Pendidikan KeSD-An, 2(2), 247-250. https://doi.org/10.30738/tc.v2i2.3142

Badan Perencanaan Pembangunan Nasional. (2017). Metadata Indikator (Tujuan Pembangunan Berkelanjutan (TPB)/ Sustainable Development Goals (SDGs) Indonesia.

DPR RI. (1999). Undang-Undang Nomor 56 Tahun 1999, pp. 1-33. Retrieved from www.dpr.go.id. 1-33.

DPR RI. (2016). Undang-Undang Republik Indonesia Nomor 8 Tahun 2016.

Firmandana, T.C., Suryanti, \& Ruswahyuni. (2014). Kelimpahan Bulu Babi (Sea Urchin) Pada Ekosistem Karang Dan Lamun Di Perairan Pantai Sundak, Yogyakarta. Diponegoro Journal of Maquares, 3(14), 41-50.

Freire, P. (2011). Pendidikan Kaum Tertindas (Ketujuh). LP3S.

Gramsci, A. (1971). Selection from the Prison Notebooks. New York: International Publishers. 
Pratama, A.T., et al., Analisis Kebutuhan Pengembangan Program Pembelajaran Biologi Ramah Anak Berbasis Lingkungan

\section{JURNAL BIOLOKUS Vol.3 (1)}

Hadi, K. (2017). Pengembangan Model Problem Based Learning Berbasis Kearifan Lokal Pada Materi Keanekaragaman Hayati Kelas X. BIOnatural, 4(2), 42-52.

Hadi, K., \& Dazrullisa. (2018). Pengembangan Bahan Ajar Biologi Berbasis Kearifan Lokal. Prosiding Seminar Nasional Biotik, 822-828.

Hapsari, N., Paidi, Subali, B., Astuti, F. E. C., Pradana, S. P., \& Antony, M. K. (2019). The TPACK Profile of Biology Teacher Based on Certification Status: A Case Study in Bantul Regency. Journal of Physics: Conference Series, 1397(1). https://doi.org/10.1088/17426596/1397/1/012055

Hw, P. (2012). Biologi, Sains, Lingkungan dan Pembelajarannya dalam Upaya Peningkatan Kemampuan dan Karakter Siswa. Prosiding Seminar Biologi, 14-18. http://jurnal.fkip.uns.ac.id/index.php/prosbi o/article/view/1011.

Irawan, A., \& Susilo, M. J. (2014). Identifikasi potensi sumber belajar biologi SMA kelas X di sekitar Gua Cerme Kabupaten Bantul untuk materi keanekaragaman jenis tumbuhan semak. Jupemasi-Pbio, 1(1), 113-116.

Irwandi, I., \& Fajeriadi, H. (2020). Pemanfaatan Lingkungan sebagai Sumber Belajar untuk Meningkatkan Minat dan Hasil Belajar Siswa SMA di Kawasan Pesisir, Kalimantan Selatan. BIO-INOVED : Jurnal Biologi-Inovasi Pendidikan, 1(2), 66-73. https://doi.org/10.20527/binov.v1i2.7859.

Kementrian Sosial. (n.d.). Sistem Informasi Penyandang Disabilitas - Kementerian Sosial RI.

Lasindrang, L. S. N. K. M. (2015). Kajian Sebaran Potensi Ekonomi Sumber Daya. Jurnal Teknosains, 4(2): 101-198. https://doi.org/10.22146/teknosains.7953

Madya, S., \& Ishartiwi. (2017). Instilling Character Values Through a Local Wisdom-Based School Sulture: An Indonesian Case Study. Proceedings of The 2nd International Conference on Teacher Education and Professional Development (INCOTEPD 2017), 371-380.
Meiningsih, D., Alimah, S., \& Anggraito, Y. U. (2019). Majalah IT-FLY VA: Alternatif Pilihan Sumber Belajar Biologi. Jurnal Phenomenon, 09(1), 1020.

Mulyono, S. E. (2017). Model Pemberdayaan Masyarakat Miskin Melalui Jalur Pendidikan Non-Formal Di Kecamatan Gajahmungkur Kota Semarang. Jurnal Edukasi, 2(1): 1-10.

Orón Semper, J. V., \& Blasco, M. (2018). Revealing the Hidden Curriculum in Higher Education. Studies in Philosophy and Education. https://doi.org/10.1007/s11217-018-9608-5

Pemerintah Kabubaten Gunungkidul. (2020). Pemerintah Kabupaten Gunungkidul. https://gunungkidulkab.go.id

Purnamasari, I., Suyata, \& Dwiningrum, S. I. A. (2017). Homeschooling Dalam Masyarakat: Studi Etnografi Pendidikan. Jurnal Pembangunan Pendidikan: Fondasi Dan Aplikasi Online, 5(1), 14-31.

Subur, Qosim, M. N., \& Nugroho, I. (2015). Implementasi Sekolah Ramah Anak Dalam Membentuk Budaya Sekolah di SDN Geger Tegalrejo. Prosiding Konferensi Nasional Ke7 Asosiasi Program Pascasarjana Perguruan Tinggi Muhammadiyah Aisyiyah (APPPTMA), 353-357.

Ro'fah, A., \& Afandi, M. (2010). Membangun Kampus Inklusif: Best Practise Pengorganisasian Unit Layanan Difabel. Yogyakarta: PSLD UIN Sunan Kalijaga.

Sudirjo, E. (2016). Model Pembelajaran Inovatif Berbasis Konsep Sekolah Ramah Anak. EduHumaniora: Jurnal Pendidikan Dasar Kampus Cibiru, 2(1), 1-11. https://doi.org/10.17509/eh.v2i1.2748

Sujarwo \& Wibawa, L. (2013). Analisis Permasalahan Perempuan Dan Potensi Lokal Di Kabupaten Gunungkidul Daerah Istimewa Yogyakarta. Jurnal Penelitian Humaniora, 18(2), 166-177.

Surtikanti, H. K. \& Bahabazi, U. (2013). Studi Tentang Ekologi dan Habitat Planaria sp. di Subang: Kelimpahan dan Biomassa Merupakan Indikator Kualitas Air Bersih. Jurnal Ekologi dan Habitat, 1(1), 66-72. https://doi.org/10.20884/1.mib.2013.30.2.12 $\underline{8}$ 
Pratama, A.T., et al., Analisis Kebutuhan Pengembangan Program Pembelajaran Biologi Ramah Anak

\section{JURNAL BIOLOKUS Vol.3 (1)}

Vitdiawati, R., Nusantari, R., \& Tyas, D. N. (2016). Pengembangan Petunjuk Praktikum Berbasis Geopark Dengan Pendekatan Inquiry Learning untuk Mata Kuliah Ekologi. Prosiding Symbion Prodi Pendidikan Biologi FKIP Universitas Ahmad Dahlan, 301-310.

Wilujeng, I., P., Z. K., \& Suryadarma, I. G. P. (2019). Integrating Local Wisdom in Natural Science Learning. Proceedings of the 1st International Conference on Innovation in Education (ICoIE 2018), 182-186.

https://doi.org/10.2991/icoie-18.2019.42

Wilujeng, I., P., Z. K., \& Suryadarma, I. G. P. (2017). Science learning based on local potential: Overview of the nature of science (NoS) achieved. AIP Conference Proceedings, 1868. https://doi.org/10.1063/1.4995189

Yustiana, I. A., Paidi, \& Mercuriani, I. S. (2018). Biology Factual Knowledge at Eleventh Grade of Senior High School Students in Pacitan based on Favorite Schools. Journal of Physics: Conference Series, 970(1). https://doi.org/10.1088/17426596/970/1/012029 